\title{
Solvent nature effect in preparation of perovskites by flame pyrolysis
}

\section{1: Carboxylic acids}

\author{
G.L. Chiarello, I. Rossetti, L. Forni*
}

Dip. Chimica Fisica ed Elettrochimica, Università degli Studi di Milano and ISTM-CNR

via C. Golgi, 19, I-20133 Milano, Italy

P.Lopinto, G.Migliavacca

Stazione Sperimentale per i Combustibili, S. Donato Milanese (Milano), Italy

\section{ABSTRACT}

The effect of a series of carboxylic acids $\left(\mathrm{C}_{2}\right.$ to $\left.\mathrm{C}_{8}\right)$, as solvents for the preparation by flame spray pyrolysis of $\mathrm{LaCoO}_{3}$ catalyst for the flameless combustion of methane, has been investigated. Acetic acid showed to be unsatisfactory from several points of view: low phase purity of the catalyst, higher amount of unburnt carbonaceous residua, lower catalytic activity and low thermal stability. By increasing the carbon chain length of the solvent, the consequent increase of flame temperature led to an increase of crystal phase purity and of particle size and to a decrease of specific surface area of the catalyst. Catalytic activity showed only marginally affected by the last parameter, phase purity seeming more important. Thermal resistance showed directly related to flame temperature, i.e. to the combustion enthalpy of the solvent, but a relatively high amount of residual organic matter can negatively affect this property.

Keywords: Perovskites; Flame spray pyrolysis; Methane catalytic flameless combustion

*Corresponding author: Fax: +39-02-50314300, e-mail: lucio.forni@unimi.it 


\section{1 - INTRODUCTION}

The catalytic flameless combustion (CFC) of hydrocarbons, particularly of methane, is gaining growing attention to produce energy by gas turbines [1-4], substantially increasing overall efficiency and decreasing noxious emissions with respect to homogeneous combustion. Indeed, the presence of a catalyst favours complete combustion, so virtually suppressing any formation of $\mathrm{CO}$ and of partially unburnt hydrocarbons, and strongly decreases $\mathrm{NO}_{x}$ formation, due to the much lower combustion temperature $[1,5]$. The catalysts traditionally employed for the present reaction are supported noble metals, among which Pd shows the most active [6-8]. However, the reaction being usually carried out at around $1000^{\circ} \mathrm{C}$, a high thermal resistance of the catalyst is also required, not easily attainable with those catalytic systems.

Among the possible substitutes for noble metals, mixed oxides of perovskitic structure can offer satisfactory activity and higher thermal resistance [9-16]. However, these properties are hardly obtainable at once by the traditional preparation methods. For instance, the calcination-milling procedure $[17,18]$ allows to synthesise highly sintered ceramic materials, characterised by good thermal stability, but unsatisfactory activity. By contrast, the various sol-gel procedures so far proposed lead to relatively high specific surface area (SSA) materials (up to ca. $30 \mathrm{~m}^{2} / \mathrm{g}$ ), with excellent initial catalytic activity, however accompanied by poor thermal resistance [9-11,14,19-22].

Different flame-based preparation techniques, e.g. flame-hydrolysis [10-15] or flame-pyrolysis [16,23-31], allow to combine the advantage of one-step preparation with the formation of nano-size powder oxides, characterised by exceptionally high SSA (even in excess of $100 \mathrm{~m}^{2} / \mathrm{g}$ ), due to the very low residence time of the precursors within the flame. Catalytic activity for CFC is only in part related to SSA, mostly depending on bulk oxygen mobility [9,32-35]. The latter in turn is related to the degree of phase purity, to the 
presence of structural defects and to the bulk/surface atomic ratio of the catalyst components.

In the recent past we set up a flame-pyrolysis (FP) apparatus for the one-step synthesis of perovskitic mixed oxides [16,23], similar to that employed for the preparation of different materials [24-26, 36-44]. The method consists of feeding an organic solution of the oxide precursors into a nozzle, co-fed with oxygen, the organic solvent acting as fuel for the main flame. After a basic optimisation of the preparation procedure, we started to analyse systematically the effect of the main operating parameters on the physicalchemical and catalytic properties of the samples obtained. The parameters so far investigated $[16,23]$ included oxygen flow rate and linear velocity, pressure drop across the nozzle, concentration and feeding rate of the organic solution. We observed that every parameter decreasing the residence time of the precursors within the flame, and/or decreasing flame temperature, and/or decreasing the concentration of the primary particles into the flame, brings about a more or less appreciable increase of catalyst SSA. Provided that a good phase purity is obtained, this can enhance catalytic activity, however accompanied by a less satisfactory thermal resistance.

In spite of a considerable number of papers dealing with the fluid dynamics of the particles in the flame $[16,23,42,44]$, scanty information is available on the effect of the nature of organic solvent on catalyst properties, particularly when dealing with mixed oxides preparation. This prompted us to carry out an extensive and systematic investigation on this topic. The effect of different solvents (either pure or mixed) on SSA, particle size, crystallinity, activity and thermal resistance of a standard perovskitic catalyst $\left(\mathrm{LaCOO}_{3}\right)$ in the CFC of methane have been investigated. In the present paper pure carboxylic acids (from $\mathrm{C}_{2}$ to $\mathrm{C}_{8}$ ) are considered as solvents. 


\section{2 - EXPERIMENTAL}

\section{1 - Catalyst preparation}

$\mathrm{La}\left(\mathrm{CH}_{3} \mathrm{COO}\right)_{3} \cdot 2 \mathrm{H}_{2} \mathrm{O}$ (Aldrich, $>99.9 \%$ pure) and $\mathrm{Co}\left(\mathrm{CH}_{3} \mathrm{COO}\right)_{2} \cdot 4 \mathrm{H}_{2} \mathrm{O}$ (Merck, purum) were dissolved in the selected solvent, so to obtain a 1:1 La:Co atomic ratio and a $0.1 \mathrm{M}$ overall metal ions concentration. The following carboxylic acids were tested: acetic, propionic, butyric, hexanoic, octanoic and 2-ethyl-hexanoic. The organic solution (2 $\mathrm{cm}^{3} / \mathrm{min}$ ), together with $5 \mathrm{~L} / \mathrm{min}$ of oxygen (SIAD, purity $>99.95 \%$ ), was fed to the burner extensively described in our previous papers $[16,23]$. The cross section area of the burner nozzle was adjusted so to have a pressure drop of 1.5 bar across the nozzle. The main flame was ignited and supported by a ring of twelve premixed $\mathrm{O}_{2}+\mathrm{CH}_{4}$ flamelets $\left(\mathrm{CH}_{4}=\right.$ $0.5 \mathrm{~L} / \mathrm{min} ; \mathrm{O}_{2}=1.0 \mathrm{~L} / \mathrm{min}$ ). The oxides powder so produced was collected by means of a $10 \mathrm{kV}$ electrostatic precipitator $[15,16]$.

High-resolution thermal maps of the flame were recorded through an infra-red Agema Thermovision 900 apparatus, equipped with close-up lens and with a data processing unit for real-time image analysis. Local values of the flame temperature were independently measured by means of a $13 \% \mathrm{Rh}-\mathrm{Pt} / \mathrm{Pt}$ thermocouple, placed inside the flame.

\section{2 - Catalyst characterisation}

SSA was measured by $\mathrm{N}_{2}$ adsorption/desorption at $77 \mathrm{~K}$ on a Micromeritics ASAP 2010 apparatus. Morphological analysis was done by a LEICA LEO 1430 scanning electron microscope (SEM). XRD analysis was made by a Philips PW1820 powder diffractometer, by using the $\mathrm{Ni}$-filtered $\mathrm{Cu}$ K $\alpha$ radiation $(\lambda=1.5148 \AA)$. The diffractograms obtained were compared with literature data for phase recognition [45]. Average crystal diameter was calculated either from BET data $\left(\mathrm{D}_{\mathrm{BET}}\right)$, or by fitting the profile of two different 
reflections $\left(2 \theta=23.3^{\circ}\right.$ and $\left.2 \theta=47.6^{\circ}\right)$ to calculate the integral peak width $(\beta(\mathrm{rad}))$ and by applying the Scherrer equation $\left(D_{X R D}(n m)=\lambda(n m) /(\beta \cdot \cos \theta)\right.$. Thermogravimetric analysis (TGA) of the as prepared powder was carried out in flowing air by means of a Perkin-Elmer TGA7 apparatus, while heating the sample $\left(10^{\circ} \mathrm{C} / \mathrm{min}\right)$ from 30 up to $800^{\circ} \mathrm{C}$. Temperature programmed oxidation (TPO) analysis was performed by means of the experimental apparatus described in detail elsewhere [46]. Briefly, ca. $0.20 \mathrm{~g}$ of catalyst were loaded into a continuous, tubular quartz microreactor, fed with $30 \mathrm{~cm}^{3} / \mathrm{min}$ of a $10 \%$ $\mathrm{O}_{2}$ in He gas mixture and heated by an electric furnace, controlled by an Eurotherm 2408 TRC, with the same temperature ramp as in TGA experiments. The composition of the outcoming gas was monitored by means of a quadrupolar mass spectrometer (QMS) (MKS, PPT Residual Gas Analyser).

\section{3 - Catalytic activity tests}

Catalytic activity for the CFC of methane was measured by temperature programmed reaction in unsteady state conditions, by means of a continuous, quartz tubular reactor (i.d.= $7 \mathrm{~mm}$ ) heated by a furnace through two heavy metal blocks. The catalyst (ca. $0.2 \mathrm{~g}, 0.15-0.25 \mathrm{~mm}$ particle size) was diluted $1: 10$ by volume with quartz particles of the same size $(1.3 \mathrm{~g})$ and kept in the isothermal middle part of the reactor by two flocks of quartz wool. The void part of the reactor tube, above and below the catalyst bed, was filled with 10-20 mesh quartz beads. Prior to each run, the catalyst was activated in flowing air $\left(20 \mathrm{~cm}^{3} / \mathrm{min}\right)$, while increasing temperature by $10^{\circ} \mathrm{C} / \mathrm{min}$ up to $600^{\circ} \mathrm{C}$, then kept for $1 \mathrm{~h}$. The activity tests were carried out by feeding a mixture composed of 0.5 vol\% $\mathrm{CH}_{4}, 49.5$ vol\% He and 50 vol\% air, while increasing temperature by $2^{\circ} \mathrm{C} / \mathrm{min}$ from 250 up to $600^{\circ} \mathrm{C}$. The out coming gas was analysed in line by means of a HP 5890 gas chromatograph, equipped with Porapak $Q$ and MS-5A columns in series. The total flow 
rate of the reactants mixture was calculated so to have for every test an identical value of time factor $\tau=W / F=10\left(\mathrm{mg}_{\text {perovskite }} \cdot \mathrm{min} / \mathrm{cm}^{3}\right.$ overall gas flow rate $)$.

\section{4 - Accelerated thermal deactivation tests}

Accelerated thermal deactivation tests were carried out after keeping the sample at the temperature $\left(\mathrm{T}_{\mathrm{f}}\right)$ of maximum conversion for $48 \mathrm{~h}$, measuring the residual conversion every $24 \mathrm{~h}$. Then cycles of reaction/deactivation were accomplished by increasing temperature $\left(10^{\circ} \mathrm{C} / \mathrm{min}\right)$ up to $800^{\circ} \mathrm{C}$, kept for $1 \mathrm{~h}$. The temperature was then dropped back to $\mathrm{T}_{\mathrm{f}}$, kept for $3 \mathrm{~h}$, during which the $\mathrm{CH}_{4}$ residual conversion was measured. The cycles were repeated for at least three times. For some of the most interesting samples the whole conversion vs. temperature curve was drawn also after the three overheating cycles.

\section{3 - RESULTS AND DISCUSSION}

\section{1 - Catalysts preparation and characterisation}

In the FP technique the organic solvent plays a double role, acting as dispersing agent for the precursor salts and as fuel for the main flame. Hence, the first point to be considered is the stability of the precursors solution in the selected solvent and consequently the proper selection of the precursor salts. For the present series of carboxylic acids $\left(\mathrm{C}_{2}\right.$ to $\left.\mathrm{C}_{8}\right) \mathrm{La}$ and $\mathrm{Co}$ acetates were selected due to their rather high solubility in those acids. All solutions showed to be stable at room temperature, except the one based on acetic acid, which needed to be heated at least at $50^{\circ} \mathrm{C}$ and kept hot during feeding, due to solubility limits of the precursors.

Some relevant properties of the solvents and of the perovskitic powders so prepared are collected in Table 1. The increase of the carbon chain length of the organic acid, accompanied by an increase of the $\mathrm{C} / \mathrm{O}$ ratio, leads to the increase of the molar 
combustion enthalpy $\left(\Delta H_{c m}\right)$. A practical parameter for the present application is the combustion enthalpy referred to the liquid solvent volume $\left(\Delta H_{c v}\right)$, which increases from 15.3 to $-30.3 \mathrm{~kJ} / \mathrm{cm}^{3}$ when passing from acetic to octanoic acid (samples 1 to 5 , Table 1 ). Furthermore, the branching of the carbon chain can affect the easiness of solvent decomposition and combustion, and of course the flame stability. Hence, linear and branched $\mathrm{C}_{8}$ acids were also compared (samples 5 and 6 , Table 1).

As extensively reported in our previous papers [16,23], many operation parameters can affect sample properties in the FP synthesis, such as pressure drop $(\Delta P)$ across the nozzle, oxygen flow rate and discharge linear velocity. To keep separated the possible effects of these parameters on the characteristics of the samples here prepared, both pressure drop across the nozzle and oxygen flow rate were kept fixed. However, when both liquid and oxygen flow rates are kept constant, then the $\mathrm{O}_{2} /$ fuel molar ratio progressively decreases with the lengthening of the carbon chain. Indeed, by defining $\Phi=\frac{\left(\mathrm{molO}_{2} / \mathrm{molfuel}\right)_{\text {real }}}{\left(\mathrm{molO}_{2} / \mathrm{molfuel}\right)_{\text {stoich }}}[16]$, this parameter decreases when passing from acetic to octanoic acid (Table 1). In the present case we let $\Phi$ vary in the over-stoichiometric range $(\Phi>1)$, checking its possible effect through a proper comparative sample prepared from octanoic acid with $\Phi=2.2$, i.e. the value used with propionic acid (catalysts 2 and 5', Table 1).

Two independent systems were used to map the temperature of the flame: an IR camera and a thermocouple. Temperature determination on the basis of IR emission only is not an easy task, because the values of the concentration of all the emitting species should be provided. In addition, a reliable calculation of the particles/gas phase heattransfer coefficient, affecting the temperature and hence emissivity of particles surface, can be done only by exactly knowing the fluid dynamics of the flame. From this point of view some uncertainty comes also from the geometry of the burner discharge section, 
leading to an uncertain value of the Reynolds number relative to the overall flow rate of reactants at the nozzle exit. Indeed, our measures seemed to underestimate flame temperature, a behaviour observed also when comparing $\mathrm{CH}_{4}$-based flames of different size. This comparison showed that temperature underestimation increases with decreasing the flame size. The IR camera was then calibrated on the values measured by the thermocouple. It should be noticed that the method needs some further refinement, because flame fluctuation leads to temperature variations even of hundreds ${ }^{\circ} \mathrm{C}$ in the worst cases. Hence, the temperature values here reported should be considered only for comparison purposes. An example of flame temperature fluctuation is reported in Table 2, showing the maximum value of flame temperature and of its standard deviation, measured with solutions prepared from propionic and octanoic acid, respectively, at different pressure drop of reactants flowing through the nozzle. As expected, the average flame temperature was higher for octanoic than for propionic acid. Moreover, the quenching effect, previously observed [16] and due to the increase of oxygen discharge velocity on going from $\Delta P=0.4$ to $1.5 \mathrm{bar}$, has been confirmed. As a consequence, the average flame temperature should be considered only indicative of the value experienced by the forming particles, due to the rather wide variation of the values measured in different points of the flame, as reported in some detail in our previous paper [23]. In addition, the temperature values measured in the same position within the flame showed that the increase of flame turbulence (higher $\Delta P$ ) leads to more homogeneous local temperature, as a consequence of the better flame mixing. Indeed, excursions of ca. 100 and ca. $200^{\circ} \mathrm{C}$, respectively, were observed for both solvents for a 1.5 bar pressure drop across the nozzle, i.e. for the highest discharge velocity, whereas this gap increased up to $500^{\circ} \mathrm{C}$ when flame turbulence was decreased ( $\triangle P=0.4$ bar). This is in line with our previous findings [16], clearly showing that the higher the flame turbulence and hence the better the internal mixing, the better was particle size homogeneity. 
An increase of flame temperature should be expected when increasing the combustion enthalpy $\left(\Delta H_{c v}\right)$ of the solvent. Flame temperature is also affected by the $\mathrm{O}_{2}$ quenching effect, which varies with $\Phi$. The effect of the increase of $\Delta H_{c v}$ at constant $\Phi$ on flame temperature can be estimated by comparing samples 2 and 5' (Table 1), whereas the comparison of samples 5 and $5^{\prime}$ gives an idea of the contribution of $\Phi$ when the same solvent is employed. As for the former point, the increase of $\Delta H_{c v}$ from ca. -20 to ca. -30 $\mathrm{kJ} / \mathrm{cm}^{3}$, when passing from propionic to octanoic acid, caused an increase of flame temperature of ca. 500 and ca. $1000^{\circ} \mathrm{C}$, at high and low pressure drop, respectively (Table 2). By contrast, the quenching effect of oxygen excess [23] was confirmed, leading to a decrease of flame temperature of $c a .100^{\circ} \mathrm{C}$ when increasing $\Phi$ from 1.5 to 2.2 .

The effect of carbon chain branching was investigated by comparing octanoic and 2-ethyl-hexanoic acid, as mentioned. $\Delta H_{c v}$ being similar (ca. $-30 \mathrm{~kJ} / \mathrm{cm}^{3}$ ), a similar flame temperature could be expected. However, a much higher temperature was obtained with the branched acid, in line with literature data referring to the combustion of linear and branched alkanes [47].

The organic counter ion of precursor salts could also act as additional fuel. Indeed, by comparing the pure fuel with a $0.1 \mathrm{M}$ solution of the precursors, the measured flame temperature increased by ca. 150 and ca. $200^{\circ} \mathrm{C}$, with propionic and octanoic acid as solvent, respectively. The same temperature increase was observed by comparing the thermal images taken by the IR camera and the temperature measured by the thermocouple.

A progressive decrease of catalyst SSA was observed with increasing the combustion enthalpy of the solvent and hence flame temperature (Table 1). The quenching and dispersing effects connected with the increase of $\Phi$ (samples 5 and 5', Table 1) allowed to sensibly increase SSA. On the other hand, the increase of flame 
temperature provided by the branched solvent with respect to the linear one led to a further drop of SSA. SEM micrographs (Fig.1) showed that every sample consisted of uniform-size spherical nano-particles, more or less aggregated into larger agglomerates. The nano-particles mean size was always much lower than $100 \mathrm{~nm}$ and showed dependent on the solvent adopted, i.e. on flame temperature. Indeed, in line with the above reported observation on SSA, an increase of the mean particle size was observed when increasing flame temperature, due to a more extensive particle coalescence and sintering. Moreover, when long chain carboxylic acids are used, decarboxylation can occur at relatively low temperature [40]. Gas evolution then can lead to droplet bursting, ending into a higher dispersion.

Samples phase purity and crystal size were checked through XRD analysis. A pure $\mathrm{LaCoO}_{3}$ phase [45] was always obtained, except when using acetic acid as solvent (Fig.2). As expected, crystal size calculated through the BET data [44] increased ongoing from sample 1 to 5 , due to the increased combustion enthalpy, leading to progressively higher flame temperature. The same order of magnitude was obtained when calculating the average crystal size through the Scherrer equation (Table 1). However, the latter data should be considered less accurate, due to problems in fitting the XRD peaks profile when excessive line broadening or peak overlapping occurred. Moreover, different size values were obtained when applying the Scherrer equation to different peaks of the same diffractogram. This reflects some structural defectivity of the samples, caused by the strain induced by the fast calcination within the flame.

Some broadening of XRD reflections was still present even for sample 5, prepared from octanoic acid, due to the nanometric size of particles for all samples. Sample 1, obtained by using acetic acid as solvent, in spite of the still relatively high flame temperature, showed a very low crystal size and a lower phase purity, witnessed by the presence of small amounts of different phases, such as $\mathrm{La}_{2} \mathrm{O}_{3}, \mathrm{La}_{2} \mathrm{CoO}_{4}$ and $\mathrm{Co}_{3} \mathrm{O}_{4}$ 
(Fig.2). This is very likely related to the much lower stability of the solution and to the higher volatility of this acid with respect to higher-molecular-weight homologous (Table 1). Similar problems were met also in the preparation of $\mathrm{Ce}_{0.5} \mathrm{Zr}_{0.5} \mathrm{O}_{2}$ [40], where it was concluded that if the solvent evaporates too quickly, lumps of precursors remain, within which the ones more easily decomposed tend to segregate. More in general, even in the case of less rapid solvent evaporation, the precursors diffusion rate within the droplet has to be compared with the mean lifetime of the droplet itself [48].

Due to the low residence time of precursors in the flame, some unburnt carbonaceous residua can still be present in fresh samples. The presence of organic residua in our samples was checked through TGA in air and TPO-QMS analysis and the results are reported in Fig.s 3 and 4. Every sample showed a more or less pronounced weight loss. TPO experiments (Fig.4) clearly showed the carbonaceous nature of the species associated with the TGA peaks (Fig.3). Most of the unburnt species could be eliminated by oxidation between 200 and $300^{\circ} \mathrm{C}$, but some samples showed an additional $\mathrm{CO}_{2}$ evolution around $550^{\circ} \mathrm{C}$, likely due to the decomposition of intermediate carbonate species. In every case, except once again for sample 1, the samples stabilised at ca. $600^{\circ} \mathrm{C}$. This means that, since $600^{\circ} \mathrm{C}$ is the activation temperature (in flowing air) of the catalyst before the activity test run, no residua are any more present on every fresh catalyst during such experiments. The amount of residua present in each sample showed not directly correlated to the carbon chain length of the solvent. Indeed, on one hand, by increasing the chain length, solvent volatility progressively decreases and the complete combustion of the solvent becomes more and more difficult. On the other hand, with increasing the combustion enthalpy, and thus flame temperature, the rate of combustion is strongly enhanced. In addition, $\mathrm{O}_{2}$ was always fed in over-stoichiometric amount, but its excess progressively decreased (decreasing of $\Phi$ ) with increasing the chain length. As a consequence, from this point of view the best compromise was obtained with butyric acid 
(Fig.3). 2-Ethylhexanoic acid led to a very low amount of carbonaceous residua, in spite of the long chain length. This can be partly due to the higher flame temperature, but also to the fact that chain branching likely leads to an increased stability of the flame (in analogy to fuels burning in internal combustion engines, due to the effect of higher octane number). Acetic acid proved to be an unsatisfactory solvent also from this point of view. Indeed, sample 1 was characterised by more than 10 wt\% unburnt material, in spite of the high volatility and easy decomposability of this acid. However, the products of combustion during the TGA and TPO experiments appeared as derived from not completely decomposed precursors, rather than from residual solvent. This is in line with the poor phase purity of this catalyst (vide supra) and with the previously suggested [40] mechanism of particles formation, witnessed by the high weight loss observed around $100^{\circ} \mathrm{C}$, attributed to water loss, accompanied by the more pronounced one after $250^{\circ} \mathrm{C}$ (Fig.4).

\section{2 - Catalytic activity and thermal stability}

The results of activity tests carried out on samples 1-5 are reported in Table 1 as values of temperature needed for attaining 50 and $100 \%$ conversion of methane $\left(T_{1 / 2}\right.$ and $T_{f}$, respectively. All the samples proved very active for the CFC of methane, leading to full conversion below $500^{\circ} \mathrm{C}$. This confirms the FP technique as a powerful method for the preparation of perovskites for this application $[16,23]$. The catalytic behaviour of this set of samples is not directly correlated to the SSA of the as prepared samples. Indeed, sample 1, prepared from acetic acid, showed the worst catalytic performance in spite of its highest SSA. Moreover, by increasing $\Phi$ for the same solvent (samples 5 and $5^{\prime}$ ), the observed increase of surface area from 43 to $66 \mathrm{~m}^{2} / \mathrm{g}$ led to only a small increase of catalytic activity (Fig.5, open dots). This is not surprising, due to the importance of bulk oxygen mobility for the intra-facial high temperature reactivity of these catalysts [12]. Indeed, the catalytic 
behaviour is rather complex, because reactivity is affected by all the factors improving ionic mobility through the lattice, as well as by those improving its surface exchange. The reaction follows a Mars-van Krevelen mechanism [9]. Thus the catalyst is involved as for its ability in both surface adsorption and release of oxygen and in oxygen migration through the bulk phase. Of course the first action is favoured by the increase of SSA, whereas the latter, predominant at high temperature, is affected by many factors, such as phase purity, presence of crystal defects, electronic and magnetic state of the lattice cations, interaction of the latter with oxygen, etc. Sample 3, prepared from butyric acid, showed the most active of the present set. The same sample showed high phase purity and the lowest amount of unburnt residua (Fig.3). The latter would not interfere with catalytic activity, being completely eliminated during the activation step (vide supra). One could hypothesise that the higher their concentration, the higher is the rearrangement needed during the activation step, in order to obtain a suitable oxygen mobility. However, sample 2, prepared from propionic acid, behaves slightly better than catalyst 5 from octanoic acid, in spite of the rather lower weight loss of the latter (Fig.3). Similar conclusions can be drawn when comparing samples 4 and 5 , whose activity was identical (Table 1), but with rather different amount of unburnt residua (Fig.3).

Chain branching seems also to play a minor role, if any, on catalytic activity. Indeed, samples 5 and 6 showed a similar activity, the sample prepared from the branched isomer being only slightly less active than that prepared from the linear one (Table 1). Finally, catalyst 6 showed lower SSA (Table 1), but higher purity with respect to catalyst 5 (Fig.3).

The results of thermal resistance tests by accelerated deactivation, for samples 1-5, are reported in Fig.6. No loss of activity was observed for every sample when keeping it at the temperature of maximum conversion $\left(T_{f}\right)$ for $48 \mathrm{~h}$. Overheating at $800^{\circ} \mathrm{C}$ for $1 \mathrm{~h}$ always caused a considerable decrease of catalytic activity. Thermal resistance showed to be correlated to the combustion enthalpy of the solvent (and hence to flame temperature). 
Indeed, sample 1 (from acetic acid as solvent) showed the lowest residual activity, whereas sample 5 (from octanoic acid as solvent) was the most stable. However, thermal stability could be correlated also to the amount of unburnt residua remaining in the sample. Indeed, a progressive decrease of activity was observed with samples 1 and 4, whose weight loss during the TGA analysis was much more pronounced (Fig.3). Though carbon impurities are burnt out during the catalyst activation preceding the activity testing run, or at least at the beginning of the reaction, their elimination very likely weakens catalyst structure, leading to a more extensive sintering, increasing with time-on-stream. This is clearly evident for samples 1 and 4 (Fig.6), whose residual activity follows the $\Delta H_{c v}$ order, but continues to decrease progressively after the second and third overheating cycles.

It is interesting to compare the conversion vs. temperature curve before and after the three overheating steps for two of the most representative samples, i.e. catalysts 2 and 5 (Fig.5). Thermal deactivation is confirmed by the $\mathrm{ca} .80-100^{\circ} \mathrm{C}$ shift to the right of both curves and sample 5 confirmed to possess the highest thermal resistance. It may be noticed that, though a severe deactivation has occurred, both the samples still show a rather high activity, leading to complete methane conversion below $600^{\circ} \mathrm{C}$, more precisely at 570 and $550^{\circ} \mathrm{C}$ for samples 2 and 5 , respectively. A similar comparison was also extended to samples 5 and 5' (Fig.5, full dots), confirming the high thermal resistance of the samples prepared from octanoic acid, though the increase of $\Phi$ entrained a quenching effect, decreasing flame temperature.

The effect of samples overheating was analysed by post-reaction characterisation and the results are here reported for brevity for sample 2 only. Particle sintering was clearly shown by XRD analysis (Fig.7). A narrowing of the reflections and an increase of their intensity was already observed after calcination at $600^{\circ} \mathrm{C}$ (simulating the activation step preceding the activity test run), but it became much more noticeable after calcination at $800^{\circ} \mathrm{C}$. Furthermore, SEM micrographs of sample 2, (a), pelletised, ground and sieved 
and $(b)$ after the three overheating cycles at $800^{\circ} \mathrm{C}$, are collected in Fig.8. Particle necking and sintering are very clearly evident after the accelerated thermal deactivation.

Finally, the decrease of surface area of samples 2 and 5 upon heating at different temperatures is shown in Fig.9. In spite of the much higher surface area of the fresh sample 2 (from propionic acid as solvent), the extent of sintering becomes similar for both the catalysts after the first heating at $600^{\circ} \mathrm{C}$, i.e. under the standard activation conditions, confirming that initial surface area is not the main parameter affecting catalytic activity.

\section{4 - CONCLUSIONS}

The present results confirm the versatility of the FP technique, which allows to impart different properties to the prepared catalyst by properly controlling the operating conditions of the burner, the selection of a proper solvent playing a major role. Acetic acid showed unsatisfactory from every point of view (need of hot injection, low phase purity of the catalyst, higher amount of unburnt residua, poor catalytic activity and lowest thermal stability). By increasing the carbon chain length of the acid, the increase of flame temperature leads to an increase of crystal phase purity and of particle size and to a decrease of SSA. The latter parameter affects only marginally activity, phase purity playing a more important role from this point of view. Thermal resistance is directly related to flame temperature, i.e. to the combustion enthalpy of the solvent, but a high residual organic material can negatively affect this property.

\section{ACKNOWLEDGEMENTS}

The financial aid of the Italian National Research Council (CNR), through the PFMSTA II programme, is gratefully acknowledged. 


\section{REFERENCES}

1. "Catalytic Combustion", P. Forzatti, G. Groppi, P. Ciambelli, D. Sannino, Eds., Polipress, Milano, Vol.1-2, 2005.

2. William \& Larson, "Aero-derivative Turbines for Stationary Power," The Center for Energy and Environmental Studies, Princeton University, May 1988.

3. W.J. Kuper, M. Blaauw, F. van der Berg, G.H. Graaf, Catal. Today, 47 (1999) 377.

4. G.B. Kauffman, Platinum Metals Rev., 43 (1999) 122.

5. H. Karim, K. Lyle, S. Etemad, L. Smith, W. Pfefferle, P. Dutta, K. Smith, ASME paper GT-2002-30083.

6. D. Ciuparu, M. R. Lyubovsky, E. Altman, L. D. Pfefferle, A. Datye, Catal. Rev., 44(4) (2002) 593.

7. P. Gélin, M. Primet, Appl. Catal. B : Environmental, 39 (2002) 1.

8. G. Centi, J. Molec. Catal. A: Chemical, 173 (2001) 287.

9. M.A. Peña, J.L.G. Fierro, Chem. Rev., 101 (2001) 1981.

10. C. Oliva, L. Bonoldi, S. Cappelli, L. Fabbrini, I. Rossetti, L. Forni, J. Molec. Catal. A: Chemical, 226 (2005) 33.

11.L. Fabbrini, A. Kryukov, S. Cappelli, G.L. Chiarello, I. Rossetti, C. Oliva, L. Forni, J. Catal., 232 (2005) 247.

12. R. Leanza, I. Rossetti, L. Fabbrini, C. Oliva, L. Forni, Appl. Catal. B: Environmental, $28(2000) 55$.

13. I. Rossetti, L. Forni, Appl. Catal. B: Environmental, 33 (2001), p. 345.

14.E. Campagnoli, A.Tavares, L. Fabbrini, I.Rossetti, Yu.A.Dubitsky, A.Zaopo, L. Forni, Appl. Catal. B: Environm., 55(2) (2005) 133.

15. R. A. M. Giacomuzzi, M. Portinari, I. Rossetti, L. Forni, Stud. Surf. Sci. And Catal., A. Corma, F.V. Melo, S. Mendioroz, J.L.G. Fierro, Eds., Vol. 130, Elsevier, Amsterdam, 2000, p.197. 
16. G.L. Chiarello, I. Rossetti, L. Forni, J. Catal., 236 (2005) 251.

17.M.F.M. Zwinkels, S.G. Järås, P.G. Menon, T. Griffin, Catal. Rev.-Sci. Eng., 35 (1993) 319

18. U. Berndt, D. Maier, C. Keller, J. Solid State Chem., 13 (1975) 131.

19. D. Ferri, L. Forni, Appl. Catal. B: Environmental, 16 (1998) 119.

20.L. Marchetti, L. Forni, Appl. Catal. B: Environmental, 15(3-4) (1998) 179.

21. Y. Shimizu, T. Murata, J. Amer. Ceram. Soc., 80 (1997) 2702.

22.F. Cifà, P. Dinka, P. Viparelli, S. Lancione, G. Benedetti, P.L. Villa, M. Viviani, P. Nanni, Appl. Catal. B: Environmental, 46 (2003) 463.

23. G.L. Chiarello, I. Rossetti, P.Lopinto, G.Migliavacca, L. Forni, Catalysis Today, 117 (2006) 549.

24. W.J. Stark, L. Mädler, S.E. Pratsinis, EP 1,378,489 A1 (2004), to ETH, Zurich.

25. H. Schultz, W.J. Stark, M. Maciejewski, S.E. Pratsinis, A. Baiker, J. Mater. Chem., 13 (2003) 2979.

26. R. Strobel, W.J. Stark, L. Mädler, S.E. Pratsinis, A. Baiker, J. Catal., 213 (2003) 296.

27.S. Kim, J.J. Gislason, R.W. Morton, X.Q. Pan, H.P. Sun, R.M. Laine, Chem. Mater., 16 (2004) 2336.

28. T. Johannessen, S. Koutsopoulos, J. Catal., 205 (2002) 404.

29. J.M. Mäkelä, H. Keskinen, T. Forsblom, J. Keskiken, J. Mater. Sci.,39 (2004) 2783.

30. A. Kilian, T.F. Morse, Aerosol Sci. and Tech., 34 (2001) 227.

31.D.J. Seo, S.B. Park, Y.C. Kang, K.L. Choy, J. Nanoparticle Res., 5 (2003) 199.

32. S. Park, J.M. Vohs, R.J. Gorte, Nature, 404 (2000) 265.

33. T. Hibino, A. Hashimoto, T. Inoue, J. Tokuno, S. Yoshida, M. Sano, Science, 288 (2000) 203. 
34.R.T. Baker, I.S. Metcalfe, P.H. Middleton, B.C.H. Steele, Sol. State Ionics, 72 (1994) 328.

35. M.S. Islam, M. Cherry, C.R.A. Catlow, J. Solid State Chem., 124 (1996) 230.

36. L. Mädler, S.E. Pratsinis, J. Am. Ceram. Soc., 85 (7) (2002) 1713.

37. R. Mueller, R. Jossen, H.K. Kammler, S.E. Pratsinis, M.K. Akhtar, AlChE J., 50(12) (2004) 3085

38. T. Tani, K. Takatori, S.E. Pratsinis, J. Am. Ceram. Soc., 87 (3) (2004) 365.

39. R. Strobel, S.E. Pratsinis, A. Baiker, J. Mater. Chem., 15 (2005) 605.

40.W.J. Stark, L. Mädler, M. Maciejewski, S.E. Pratsinis, A. Baiker, Chem. Commun., (2003) 588.

41.R. Mueller, R. Jossen, S.E. Pratsinis, M. Watson, M.K. Akhtar, J. Am. Ceram. Soc., 87(2) (2004) 197.

42. W.J. Stark, K. Wegner, S.E. Pratsinis, A. Baiker, J. Catal., 197 (2001) 182.

43.R. Jossen, S.E. Pratsinis, W.J. Stark, L. Mädler, J. Am. Ceram. Soc., 88 (2005) 1388.

44. L. Mädler, H.K. Kammler, R. Mueller, S.E. Pratsinis, J. Aerosol Sci., 33 (2002) 369.

45. Advanced Selected Powder Diffraction Data, Miner. DBM (1-40), J.C.P.D.S., Swarthmore, PA, 1974-1992.

46. L. Forni, M. Toscano, P.Pollesel, J. Catal., 130 (1991) 392.

47.B. Lewis, G. Von Elbe, "Combustion, Flames and Explosions of Gases", Academic Press, New York, 1961, Appendix C, Table 1, p. 706.

48. M.C. Heine, S.E. Pratsinis, Ind. \& Eng. Chem. Res., 44 (2005) 6222. 
Table 1. Relevant properties of the solvents employed and of the catalysts prepared. $T_{1 / 2}$ and $T_{f}$ represent the reaction temperature values needed for attaining 50 and $100 \%$ conversion of $\mathrm{CH}_{4}$, respectively. Average crystal size determined from BET data (D and by applying the Scherrer equation to two selected XRD reflections: $2 \theta=23.3^{\circ}$ (DXRD1) and $47.6^{\circ}\left(\mathrm{D}_{\mathrm{XRD} 2}\right)$

\begin{tabular}{|c|c|c|c|c|c|c|c|}
\hline sample & 1 & 2 & 3 & 4 & 5 & $5^{\prime}$ & 6 \\
\hline $\begin{array}{c}\text { Solvent / } \\
\text { fuel }\end{array}$ & $\begin{array}{c}\text { Acetic } \\
\text { acid (AA) }\end{array}$ & $\begin{array}{l}\text { Propionic } \\
\text { acid (PA) }\end{array}$ & $\begin{array}{c}\text { Butyric } \\
\text { acid (BA) }\end{array}$ & $\begin{array}{l}\text { Hexanoic } \\
\text { acid }(H A)\end{array}$ & $\begin{array}{l}\text { Octanoic } \\
\text { acid }(O A)\end{array}$ & $\begin{array}{l}\text { Octanoic } \\
\text { acid }(\mathrm{OA})\end{array}$ & $\begin{array}{l}\text { 2-Etylhexanoic } \\
\text { acid (2EHA) }\end{array}$ \\
\hline $\begin{array}{c}\text { MW } \\
{[\mathrm{g} / \mathrm{mol}]}\end{array}$ & 60.05 & 74.08 & 88.11 & 116.16 & 144.21 & - & 144.21 \\
\hline $\begin{array}{l}\text { Solvent } \\
\text { density } \\
{\left[\mathrm{g} / \mathrm{cm}^{3}\right]}\end{array}$ & 1.05 & 0.99 & 0.96 & 0.93 & 0.91 & - & 0.90 \\
\hline $\begin{array}{l}\text { Solvent } \\
\text { bp }\left[{ }^{\circ} \mathrm{C}\right]\end{array}$ & 118 & 141 & 162 & 203 & 237 & - & 228 \\
\hline $\begin{array}{c}\Delta H_{c m} \\
{[\mathrm{~kJ} / \mathrm{mol}]}\end{array}$ & -876.1 & -1536.4 & -2183.5 & -3494.3 & -4797.9 & - & -4799.6 \\
\hline $\begin{array}{c}\Delta H_{c v} \\
{\left[\mathbf{k J} / \mathbf{c m}^{3}\right]}\end{array}$ & -15.3 & -20.6 & -23.8 & -28.0 & -30.3 & -30.3 & -30.1 \\
\hline$\phi$ & 2.9 & 2.2 & 1.9 & 1.8 & 1.5 & 2.2 & 1.5 \\
\hline $\begin{array}{c}\text { SSA } \\
{\left[\mathrm{m}^{2} / \mathrm{g}\right]}\end{array}$ & 57 & 56 & 53 & 48 & 43 & 66 & 38 \\
\hline$D_{B E T}[\mathrm{~nm}]$ & 14.4 & 14.6 & 15.5 & 17.2 & 19.1 & - & 21.9 \\
\hline $\begin{array}{c}D_{X R D 1} \\
{[\mathrm{~nm}]}\end{array}$ & 15.7 & 17.8 & 16.5 & 12.7 & 17.4 & - & 21.6 \\
\hline $\begin{array}{c}D_{X R D 2} \\
{[\mathrm{~nm}]}\end{array}$ & 10.5 & 12.6 & 14.7 & 11.1 & 13.6 & - & 13.0 \\
\hline $\mathrm{T}_{1 / 2}\left[{ }^{\circ} \mathrm{C}\right]$ & 392 & 380 & 365 & 385 & 385 & 380 & 395 \\
\hline $\mathrm{T}_{\mathrm{f}}\left[{ }^{\circ} \mathrm{C}\right]$ & 490 & 460 & 450 & 480 & 480 & 458 & 492 \\
\hline
\end{tabular}


Table 2. Maximum flame temperature $\left({ }^{\circ} \mathrm{C}\right)$, averaged on 7 reading points, as measured by the IR camera for two different solvents and different pressure drop across the nozzle.

Propionic acid Octanoic acid

\begin{tabular}{|c|c|c|c|c|c|}
\hline$\Delta P$ bar & $(\text { Tmax })_{\text {av. }}$ & s.d. & $\Delta P$ bar & $(\text { Tmax })_{\text {av. }}$ & s.d. \\
\hline 1.5 & 1403 & 105 & 1.5 & 1997 & 105 \\
\hline 0.4 & 1567 & 243 & 0.4 & 2564 & 130 \\
\hline
\end{tabular}




\section{FIGURE CAPTIONS}

Fig.1: SEM micrographs of $\mathrm{LaCoO}_{3}$ samples. Figures refer to samples number (Table 1). Fig.2: XRD patterns of samples 1 (lower pattern) and 5 (upper pattern) (Table 1) (*) $\mathrm{La}_{2} \mathrm{CoO}_{4},(+) \mathrm{Co}_{3} \mathrm{O}_{4},(\mathbf{x}) \mathrm{La}_{2} \mathrm{O}_{3}$.

Fig.3: TGA patterns in flowing air. Temperature ramp: $10{ }^{\circ} \mathrm{C} / \mathrm{min}$ from r.t. to $700^{\circ} \mathrm{C}$. Figures refer to samples number (Table 1).

Fig.4: $\mathrm{O}_{2}, \mathrm{H}_{2} \mathrm{O}$ and $\mathrm{CO}_{2}$ evolution vs. temperature, measured by QMS analysis (left scale) and differential pattern of wt.\% loss (DTG) of sample 1 powder (right scale).

Fig.5: Catalytic activity pattern for CFC of $\mathrm{CH}_{4}$ of samples: 2 (prepared from propionic acid; $\phi=2.2), 5(\phi=1.5)$ and 5' ( $\phi=2.2)$ (prepared from octanoic acid). Open dots $(A)$ standard test; full dots $(B)$ after the third accelerated deactivation cycle at $800^{\circ} \mathrm{C}$.

Fig.6: Thermal stability of the various samples. The last three points of each curve show the residual $\mathrm{CH}_{4}$ conversion after the three successive accelerated deactivation cycles at $800^{\circ} \mathrm{C}$.

Fig.7: XRD patterns of sample 2: (a) as prepared, (b) after calcination at $600^{\circ} \mathrm{C}$ for $1 \mathrm{~h},(c)$ after calcination at $800^{\circ} \mathrm{C}$ for $3 \mathrm{~h}$.

Fig.8: SEM micrographs of catalytic bed particle prepared from sample 2: (a) after the standard activity test; $(b)$ after three successive deactivation cycles at $800^{\circ} \mathrm{C}$.

Fig.9: Effect of calcination temperature on SSA of sample 2 and sample 5. Heat treatment for 1 hour at the indicated temperature. 
Fig. 1
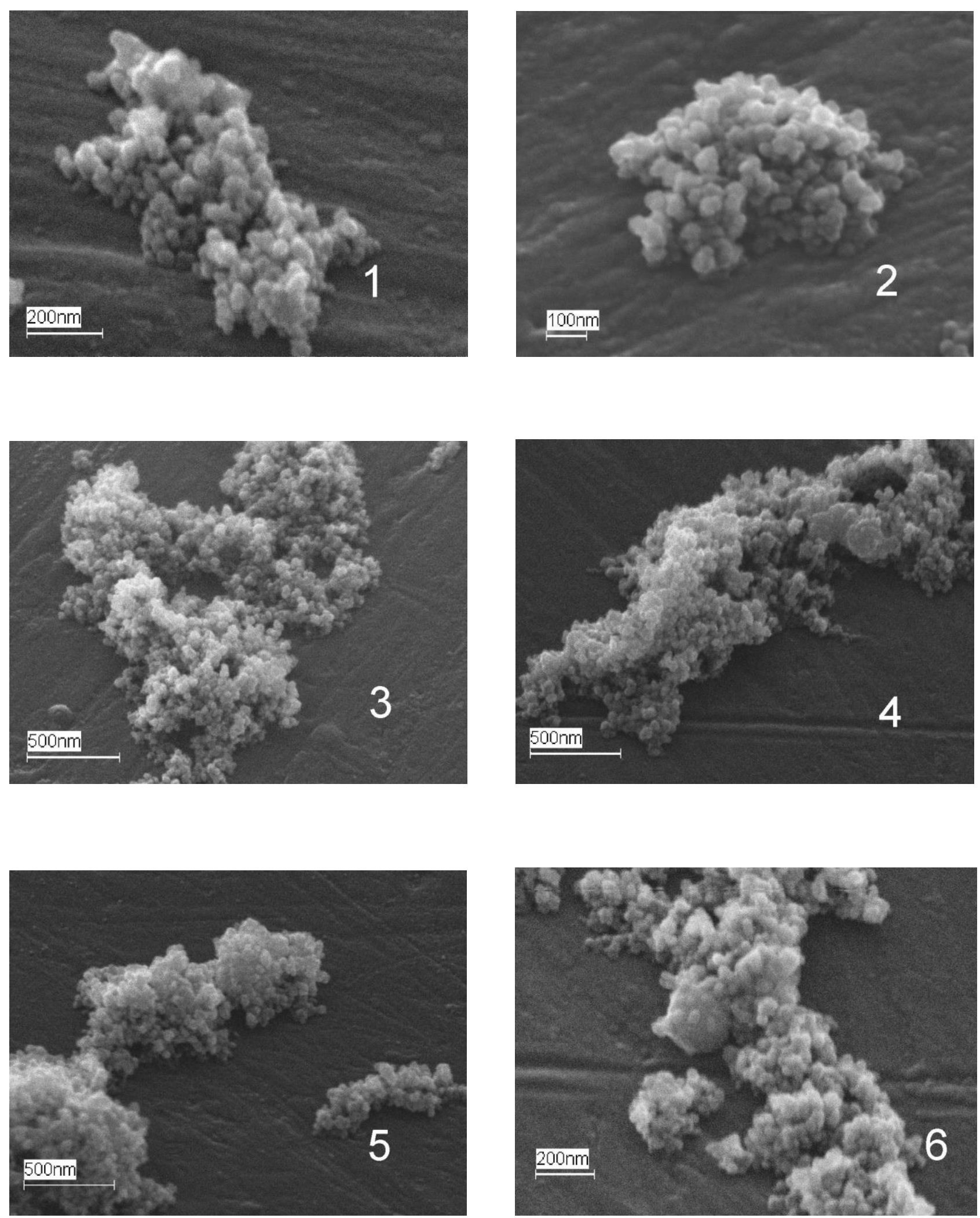
Fig.2

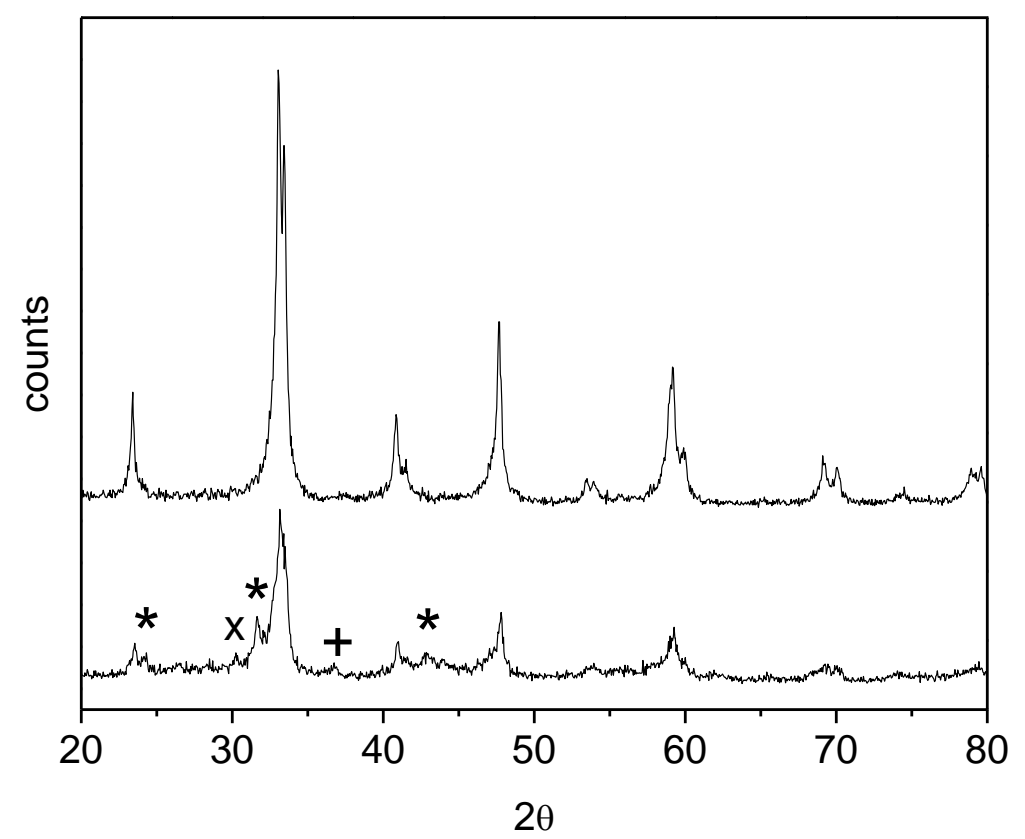


Fig.3

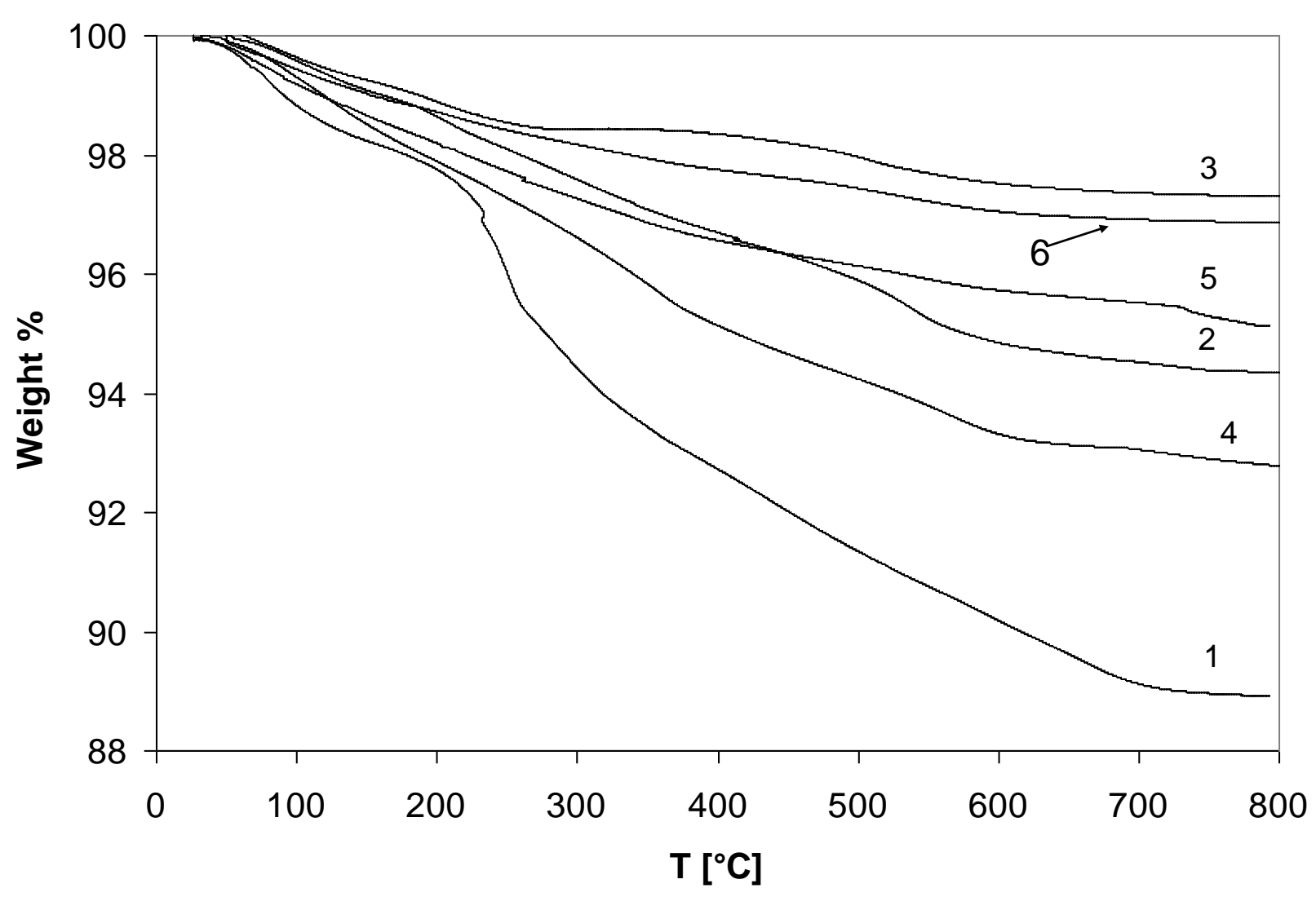


Fig.4

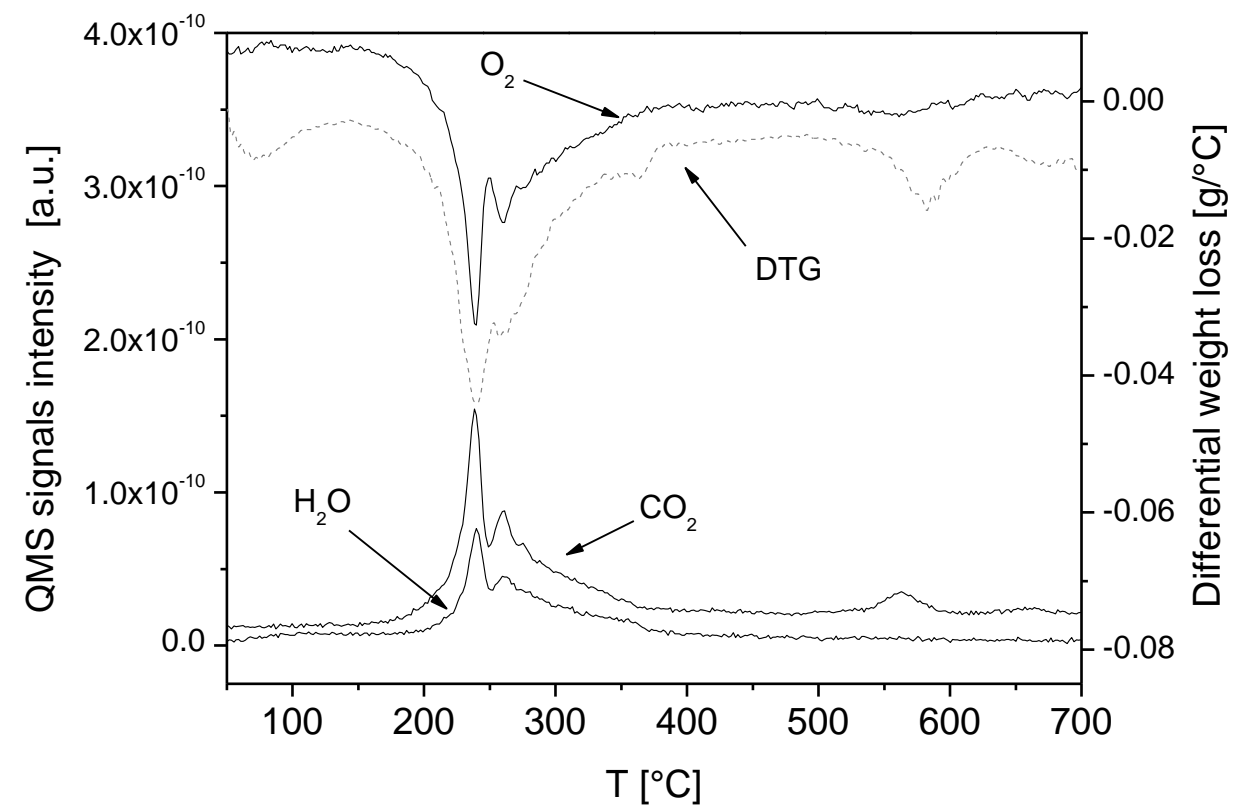


Fig.5

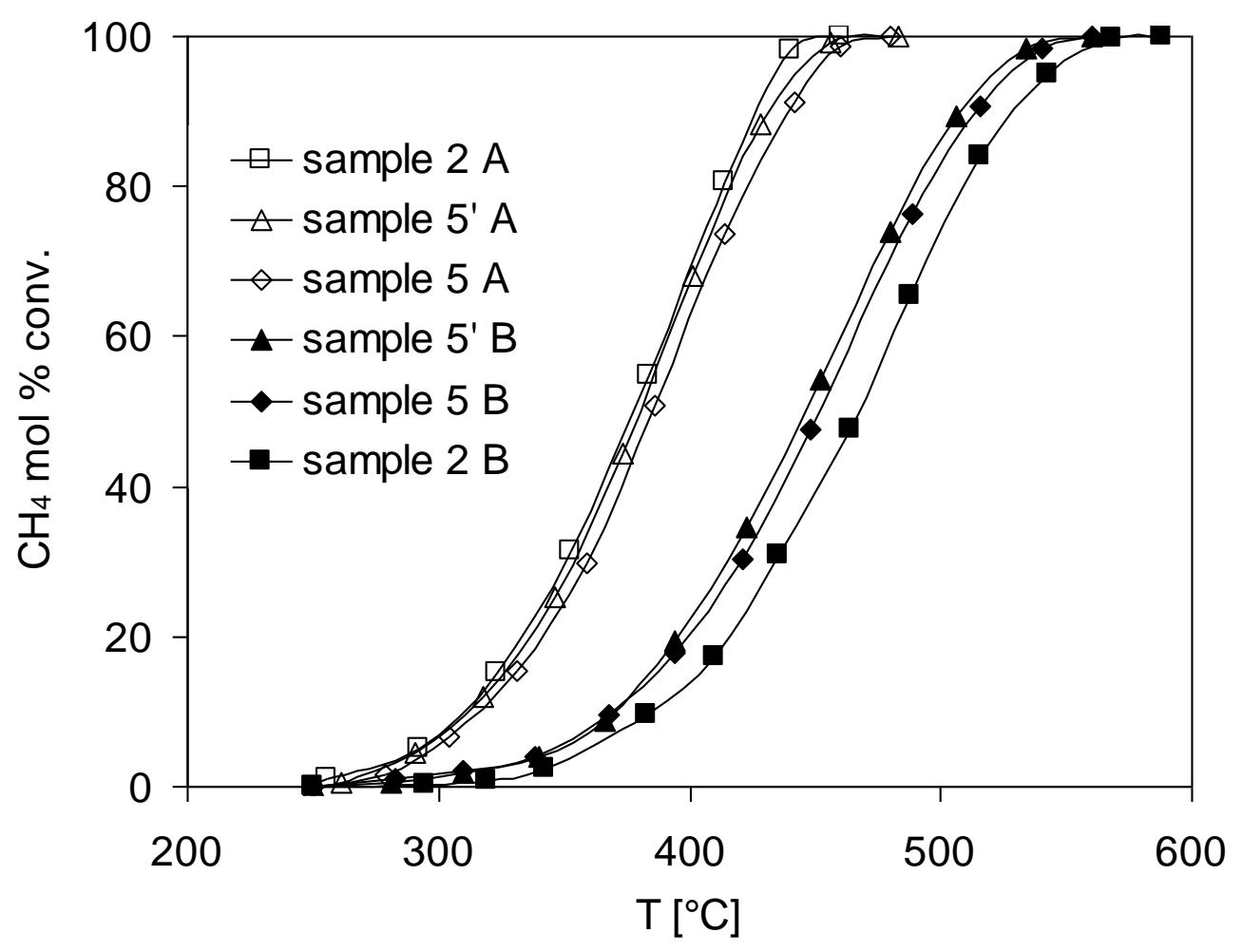


Fig. 6

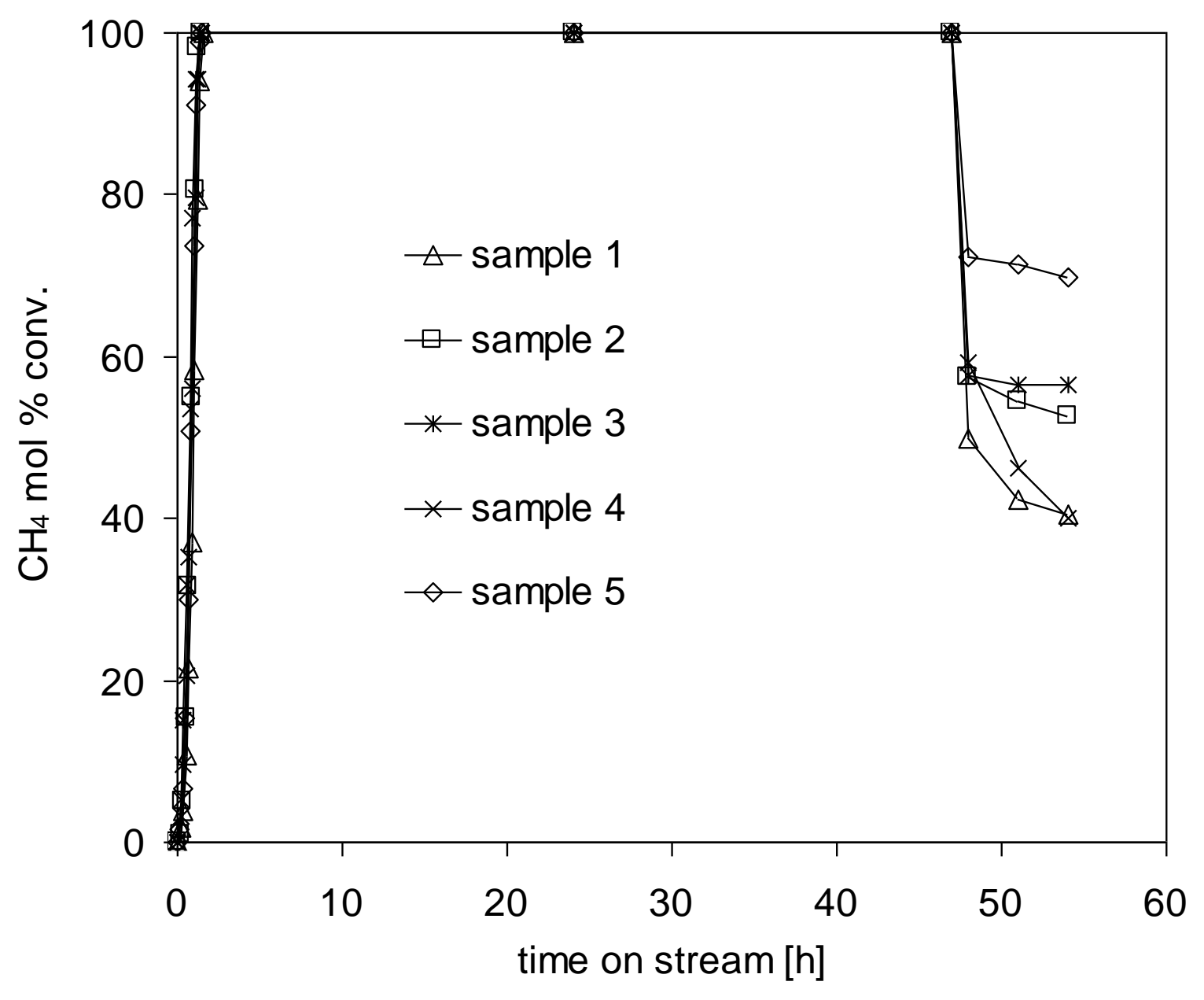


Fig. 7

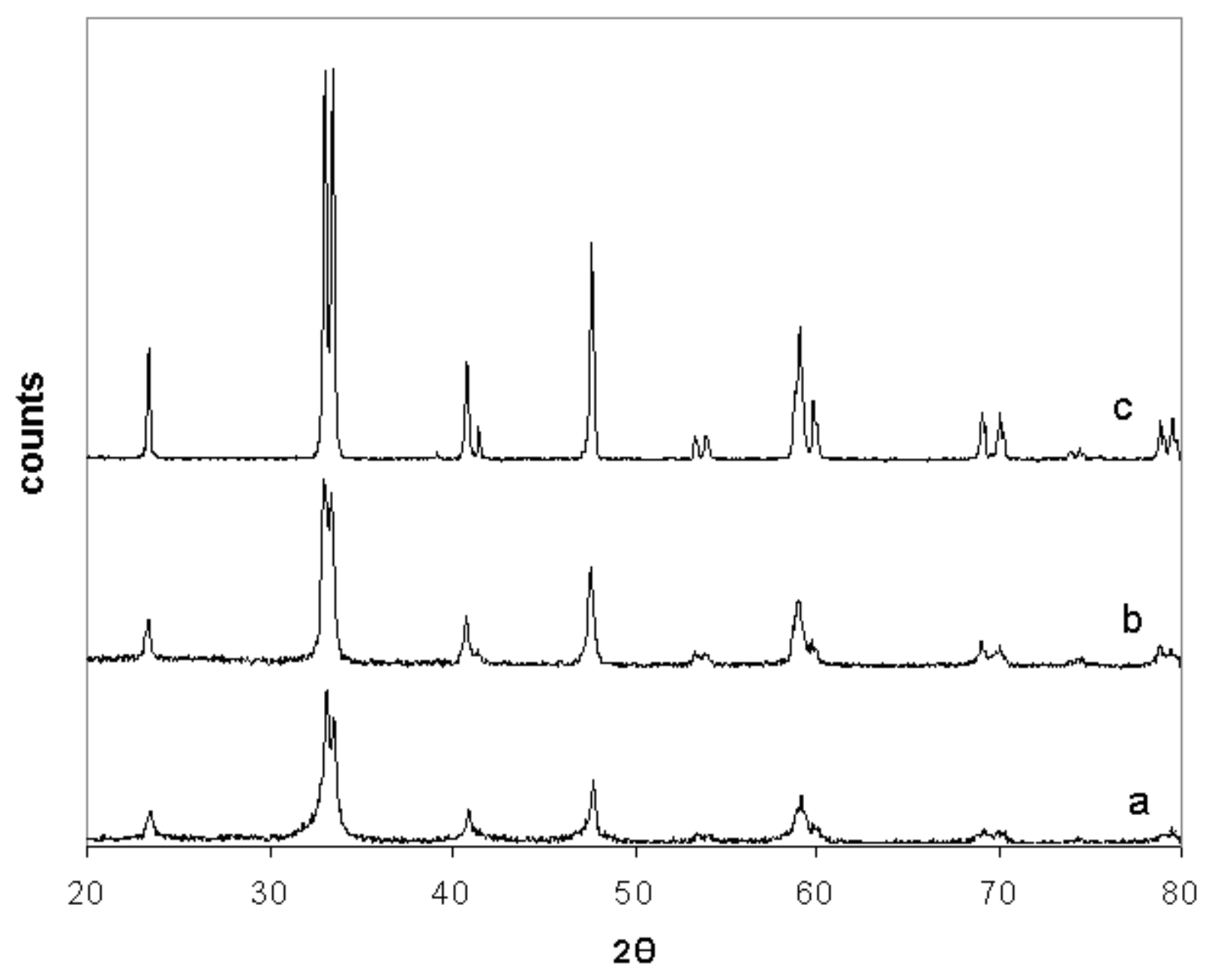


Fig.8
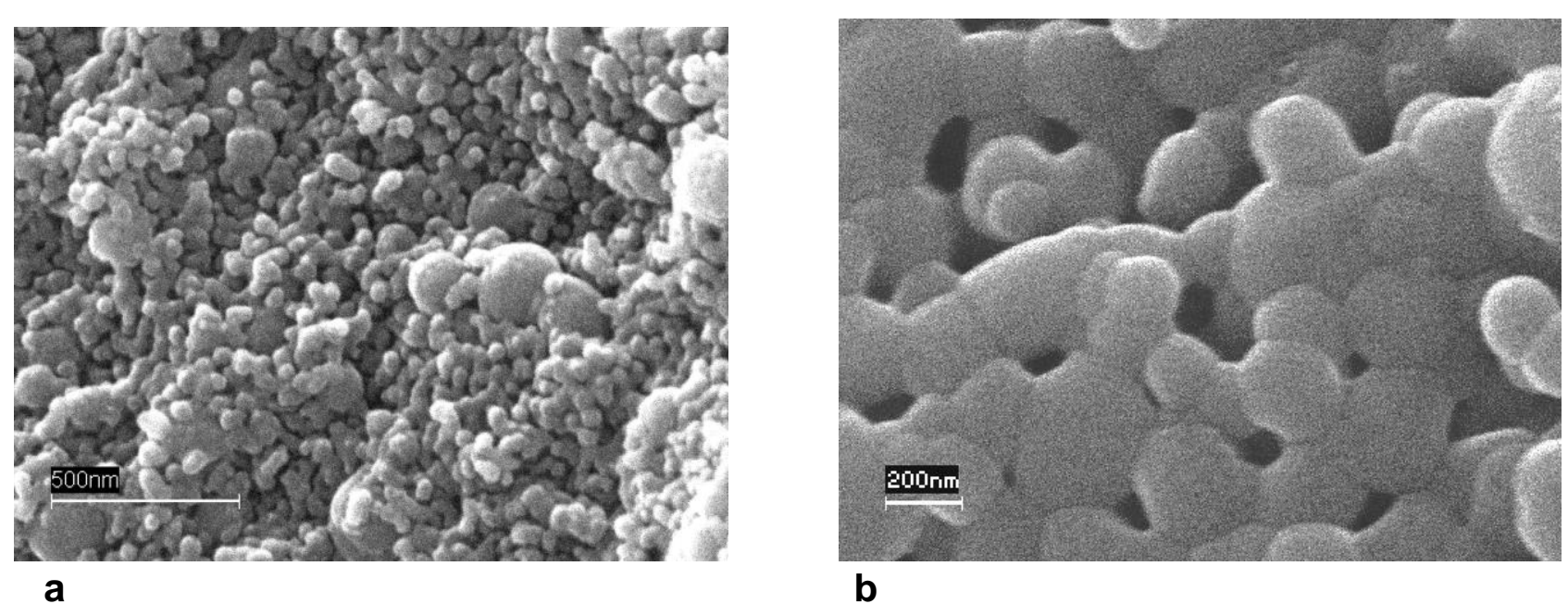

b 
Fig.9

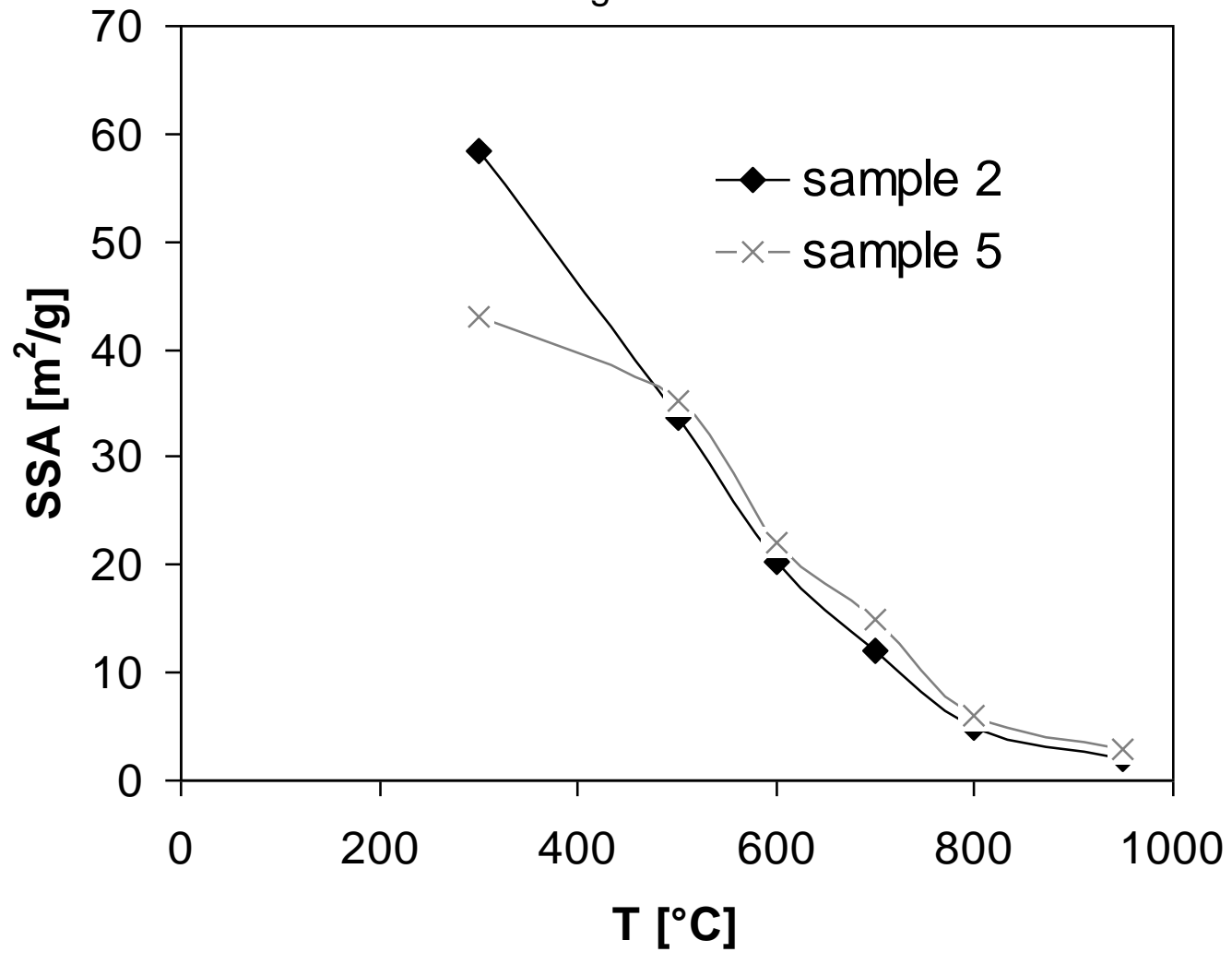

